ISSN: $1130-2887$

DOI: http://dx.doi.org/10.14201/alh2015691733

\title{
ENTRE LAS POLÍTICAS POR EL AGUA Y LOS ESFUERZOS POR CALMAR LA SED. EL «ACUEDUCTO DEL DESIERTO» EN LAS TIERRAS SECAS NO IRRIGADAS DE LAVALLE, MENDOZA
}

Between water policies and efforts to calm thirst: the «aqueduct of the desert» in the unirrigated drylands of Lavalle, Mendoza

\author{
María Virginia GROsSO CEPPARO \\ Universidad Nacional de Cuyo, Argentina \\ \rossovirginia@gmail.com \\ Laura María TORRES \\ Consejo Nacional de Investigaciones Científicas y Técnicas (CONICET), Argentina \\ $\triangle$ ltorres@mendoza-conicet.gob.ar
}

BIBLID [1130-2887 (2015) 69, 17-33]

Fecha de recepción: 11 de junio del 2014

Fecha de aceptación: 15 de enero del 2015

RESUMEN: El «acueducto del desierto» se presenta como una obra hídrica necesaria y emblemática para la zona no irrigada del departamento de Lavalle, Mendoza. Sin embargo, a casi diez años del inicio de su diseño y construcción, se encuentra desarticulada de la política hídrica provincial y exhibe limitaciones para resolver problemas estructurales como las disputas por el agua entre oasis-tierras no irrigadas, la escasez hídrica y la reparación histórica a la injusticia ambiental del lugar.

Palabras clave: agua potable; políticas; infraestructura; tierras secas; injusticia ambiental; Mendoza.

ABSTRACT: The «aqueduct of the desert» is a necessary and iconic water works for the unirrigated area of the department of Lavalle, Mendoza. However, nearly ten years on from the beginning of its design and construction, it is disconnected from the provincial water policy and 
MARÍA VIRGINIA GROSSO CEPPARO Y LAURA MARÍA TORRES ENTRE LAS POLÍTICAS POR EL AGUA Y LOS ESFUERZOS POR CALMAR LA SED

exhibits structural limitations which impede the solving of problems such as water disputes between unirrigated oasis-lands, water scarcity, and historical reparation to environmental injustice.

Key words: drinking water; policies; infrastructure; drylands; environmental injustice; Mendoza.

\section{INTRODUCCIÓN ${ }^{1}$}

Mendoza, provincia ubicada en el centro oeste de la República Argentina, al pie de los Andes centrales y en la denominada «diagonal árida sudamericana», presenta rasgos de marcada aridez que han ejercido importantes efectos sobre la vida y economía de sus tierras. Los magros 200 milímetros $(\mathrm{mm})$ que precipitan al año han hecho necesaria la sistematización y regulación de sus ríos cordilleranos y han impulsado la extracción de agua subterránea.

En este contexto de fuerte aridez, la apropiación, sistematización y distribución del agua, junto con su correspondiente andamiaje político-institucional, producen un territorio claramente fragmentado y desigual en el que las tierras secas ${ }^{2}$ irrigadas, denominadas oasis, ocupan sólo el 4,8\% de la superficie de Mendoza ${ }^{3}$ y albergan a más del $90 \%$ de un total de 1.741.610 habitantes que viven en la provincia (INDEC 2010). En estos pequeños vergeles se concentran importantes áreas urbanas y núcleos agroindustriales de gran dinamismo, consumo hídrico e impacto ambiental como así también las mayores inversiones en obra pública. El resto del territorio -tierras secas no irrigadasse compone de planicies y cordones montañosos donde habita el 10\% de la población y donde escasean las políticas orientadas a la producción y a los servicios.

En las tierras secas no irrigadas del noreste provincial, departamento de Lavalle, se ha construido recientemente un acueducto destinado a dotar de agua potable a sus habitantes rurales. Iniciado en 2007, el denominado «acueducto del desierto» atraviesa las arenosas e hiperáridas tierras de Lavalle, territorio confín de la principal cuenca de la provincia, el río Mendoza. Su ubicación «aguas abajo» del oasis del río Mendoza, junto a una historia de desigualdad en la apropiación y uso del agua, son algunas de las razones por las que en la actualidad los caudales del río se extinguen antes de llegar

1. Las autoras agradecen los comentarios y las sugerencias de dos evaluadores anónimos de América Latina Hoy, Revista de Ciencias Sociales, a la primera versión de este artículo.

2. Formalmente, la definición abarca todas las tierras donde el clima se clasifica como seco: desde el hiperárido, árido y semiárido al subhúmedo seco. Esta clasificación se basa en la relación media anual entre la precipitación de un área y su evapotranspiración potencial (índice de aridez, IA). El IA es utilizado por la Convención de las Naciones Unidas en la Lucha contra la Desertificación (UNCD), a fin de clasificar las regiones en base a la categoría de aridez. De acuerdo con esta clasificación y según los resultados de la Evaluación de los Ecosistemas del Milenio (EM, 2005), las tierras secas se extienden sobre el $41 \%$ del planeta -casi la mitad de la superficie terrestre- y en ellas residen más de dos mil millones de personas, un tercio de la población humana. En las tierras secas se encuentra el $44 \%$ de los ecosistemas cultivados del mundo y producen el $30 \%$ de las cosechas que se consumen (E. ABRAHAM et al. 2014).

3. La superficie de Mendoza es de $148.827 \mathrm{~km}^{2}$, el 5,4\% del territorio nacional. 
a esas latitudes, generando así graves perjuicios económicos, sociales, culturales y ambientales para los pobladores de estas tierras. Por su parte, la presencia de arsénico en los acuíferos dificulta que las lluvias y caudales superficiales puedan ser fácilmente reemplazados. Para los actores gubernamentales, en particular aquellos que trabajaron en su diseño y construcción, el acueducto constituye una obra emblemática no sólo por su envergadura y los altos costos económicos que su ejecución supone, sino además por las enormes repercusiones que tendrá en la calidad de vida y en la salud de los pobladores.

A casi diez años del inicio de su diseño (2002) y construcción (2007), los datos colectados en campo, en el marco de procesos de investigación en curso, permiten observar que el acueducto se presenta también como una obra paradójica. Necesaria y «de gran envergadura y trascendencia» para los organismos públicos de Lavalle, desarticulada de la política hídrica provincial y con limitaciones para resolver las grandes inequidades que la región exhibe en materia de apropiación y distribución de aguas entre oasis y tierras no irrigadas, para otros. Una obra, en definitiva, que probablemente calme la sed sin que alcance para actuar en el sentido de la reparación histórica a la injusticia ambiental.

Frente a la ausencia de trabajos de investigación que den cuenta de esta problemática, este trabajo propone problematizar los dispositivos tecnológicos propuestos por el Estado para resolver los problemas hídricos en tierras secas, por considerar que las respuestas derivadas de la hegemonía de las grandes obras ingenieriles no siempre y menos aún, por sí solas, son capaces de extender los principios de la soberanía hídrica. A partir del «acueducto del desierto» interesa considerar, en clave territorial, las dimensiones políticas de dispositivos que se presentan como soluciones a la «falta de agua» preguntándose si se está frente a políticas por el agua, dispuestas a extender y profundizar los principios de la soberanía hídrica, o frente a políticas tendientes sólo a calmar la sed.

Para ello, se han realizado entrevistas en profundidad a funcionarios públicos vinculados a la etapa de diseño, construcción y gestión del acueducto y a los pobladores provistos por la obra. Estas indagaciones se han complementado con el análisis de distintas fuentes secundarias, entre las que destacan artículos periodísticos recientes y diversos documentos oficiales.

\section{LA CUENCA INFERIOR DEL RÍO MENDOZA: TIERRAS SECAS NO IRRIGADAS DE LAVALLE}

Las condiciones de aridez imperantes en la provincia se agudizan en el extremo noreste, departamento de Lavalle. Este territorio representa el 6,8\% de la superficie provincial y su centro cabecera se ubica a sólo 34 kilómetros de la ciudad de Mendoza. Alberga en su interior una extensa área no irrigada y una historia y un presente vinculados a los huarpes, pobladores originarios de estas tierras que aprovecharon la riqueza de un «rosario» de lagunas generadas por la confluencia de los ríos Mendoza y San Juan y alrededor del curso del río Desaguadero.

El patrón de fragmentación territorial que se observa a nivel provincial se reproduce a nivel departamental. De esta manera, el oasis bajo riego de Lavalle comprende tan 
sólo el 3\% de la superficie departamental y concentra el $88 \%$ de la población urbana y rural. La zona no irrigada, por su parte, abarca el $97 \%$ de la superficie departamental, contiene el $12 \%$ de la población del departamento (3.300 habitantes) con una densidad poblacional promedio de 0,33 habitantes por $\mathrm{km}^{2}$.

En la zona no irrigada de Lavalle se desarrolla una economía pastoril centrada en la producción de ganado caprino organizada en torno a «puestos»; categoría nativa con la que se indican las unidades domésticas de producción y alojamiento familiar sobre las que pivotan los procesos de reproducción social. El espacio socioproductivo se organiza en base a la propiedad colectiva del territorio, situación que revierte en la inexistencia de alambrados y límites fijos al pastoreo. Las características que asume la producción caprina en la zona permiten situar a los productores en la categoría de campesinos, por cuanto reúnen los elementos básicos que varios autores identifican como centrales (Hocsman 2003). La actividad se desarrolla en unidades de producción que no alcanzan las fases de acumulación de excedentes y se alimenta del trabajo de los miembros de la familia. Las unidades domésticas se comportan como unidades de producción y consumo, una parte significativa de los ingresos derivan de la actividad pecuaria, poseen los medios de producción, ejercen el control formal del proceso de producción y se articulan de manera subordinada con el mercado.

En el medio local esta porción del territorio lavallino es habitualmente nombrada como «desierto». Las condiciones naturales en parte confirman esta apreciación ya que las características de aridez generales en la provincia se ven potenciadas en este espacio que presenta un promedio de precipitaciones por debajo $(120 \mathrm{~mm})$ de la media provincial $(200 \mathrm{~mm})$. Otra variable climática importante está dada por la temperatura media anual que, con medias de $16.3^{\circ} \mathrm{C}$, registra máximas absolutas de $43{ }^{\circ} \mathrm{C}$ y mínimas absolutas de $-7^{\circ} \mathrm{C}$; amplitud térmica propia del clima desértico. Sin embargo, al recorrer el área y al conversar con sus pobladores, la denominación «desierto» entra en conflicto (Grosso 2013). Si bien este término alude a un ecosistema con características de aridez, su uso a lo largo de la historia argentina y mendocina como terras nullis ${ }^{4}$ y la tendencia actual a ver en él homogeneidades que resultan de la sumatoria de carencias han invisibilizado sus particularidades y riquezas.

$\mathrm{Al}$ interior de la llanura, la población se localiza prioritariamente en pequeños poblados concentrados sobre las márgenes de los ríos Mendoza y Desaguadero o sobre los bordes de las lagunas que ocasionalmente éstos alimentan. Alejados de los cursos de agua, un centenar de unidades de producción dispersas - puestos- se localizan cercanas a los paleocauces que tatuó el río Mendoza a lo largo de los siglos XVII y XVIII (Abraham 1989)5. En ambos

4. Recostada sobre la asociación desierto/improductivo, esta noción alude a la representación y designación de un espacio como poblacionalmente vacío, culturalmente atrasado y económicamente improductivo (A. BALAZOTE y J. C. RADOVICH 2004; J. C. RADOVICH y A. BALAZOTE 2001). A lo largo de la historia argentina, con particular fuerza en el contexto de la Campaña del Desierto pero también estratégicamente reactualizada en el presente, hace parte de un dispositivo argumental disciplinador funcional a la expansión territorial del capital.

5. De acuerdo con E. M. ABRAHAM (1989), hacia el s. XVII el río Mendoza unía su curso al río Tunuyán y ambos discurrían hacia el este. Entre los siglos XVII y XVIII, el río Mendoza se desplaza 
casos se trata de localizaciones estratégicas respecto de las fuentes de agua, bien porque permiten el acceso a las temporarias aguas superficiales que fluyen por el curso de los ríos o que quedan esporádicamente contenidas en las lagunas y bañados; bien porque facilitan la extracción, utilización y calidad de las aguas subterráneas (Torres 2008: 51).

$\mathrm{El}$ hecho de que en el presente las aguas superficiales fluyan al tramo inferior de la cuenca sólo frente a sobrantes en el tramo superior no debe entenderse como un proceso de disminución de caudales de estricta causalidad climática. Muy por el contrario, es el uso intensivo realizado en el tramo superior del río Mendoza, destinado al desarrollo urbano, rural e industrial del oasis y plenamente vinculado a las opciones políticas de desarrollo regional por las que optó la provincia, el que en primer lugar explica la mengua de los caudales «aguas abajo», hasta llegar a la práctica desaparición del mismo en su paso por la zona de estudio. En tiempos de la conquista, el río Mendoza alimentaba con regularidad el rosario de lagunas ubicadas en los límites entre las actuales provincias de Mendoza, San Juan y San Luis.

Hacia el siglo XIX y particularmente a lo largo del siglo XX, Mendoza se acopla al modelo de desarrollo nacional -centrado en la producción de productos primarios con destino a los mercados mundiales- y se orienta a la producción e industria vitivinícola, evitando de este modo entrar en competencia con otras regiones productoras de Argentina (Campi y Richard Jorba 2004; Richard Jorba 2004). En este contexto, los territorios mendocinos se (re-des) territorializan a partir de un rico despliegue de recursos técnicos, pero también institucionales, organizacionales, legales y políticos, que permiten la construcción del llamado «modelo vitivinícola tradicional». Entre otros, el recurso agua será de los más afectados por cuanto será objeto de un extenso proceso de acaparamiento de aguas en la cuenca superior del río, en lo que tal vez constituya uno de los ejemplos paradigmáticos que aporta Mendoza de conversión de bienes comunes a bienes públicos de uso privado.

Creado en 1894 a instancias de la Ley de Aguas (1984), el Departamento General de Irrigación (DGI) es el órgano encargado de la administración general de las aguas y responsable de considerar y resolver todos los asuntos atinentes a las mismas dentro del territorio provincial. Es, además, el administrador mayorista del agua en la provincia y quien, en acuerdo con el Poder Ejecutivo, concibe la política hídrica provincial (Chambouleyron 2004). Su objetivo principal es la preservación, distribución y regulación de las aguas superficiales y subterráneas, a fin de aprovechar todos sus usos posibles, ejerciendo el control directo respecto a las concesiones otorgadas y aquellas que se deban otorgar, a través de estudios científicos previos (DGI 2006). Se trata de un organismo

hacia el norte hasta unirse con el río San Juan e integrar juntos la cuenca del río Desaguadero. Medido en tiempos históricos, no se trató de un cambio ambiental rápido. El río fue desplazándose ayudado por la alternancia de ciclos secos y lluviosos. En tiempos de sequía, los bordes del río se colmaban de depósitos de suelo que sólo eran arrastrados al curso anterior cuando la fuerza del agua que descendía de la cordillera así lo permitía. Con el paso del tiempo, el curso del río Mendoza se irá fijando al curso actual y esas huellas intermedias que su constante fluctuación imprimían sobre el territorio constituirán los paleocauces, localización que hoy se privilegia para maximizar la captación de aguas subterráneas. 
descentralizado y autárquico que sanciona su propio presupuesto de gastos y cálculo de recursos, a través de la recaudación del pago del agua por los regantes. Para ello, el empadronamiento permite que los usuarios tributen al DGI por el agua que utilizan en virtud de las hectáreas de su propiedad (Bustos et al. 2006).

El agua en Mendoza constituye un bien de dominio público, por lo que el DGI prevé que su administración se realice de forma democrática, para lo cual en teoría garantiza la participación de los usuarios a través de las denominadas inspecciones de cauce $^{6}$; agrupaciones de regantes organizadas por cuenca en la que pequeños, medianos y grandes usuarios pueden discutir la distribución del recurso, entre otras temáticas ${ }^{7}$. Llamativamente, y sin embargo, los contornos de la participación en el DGI asignan derecho al voto a quienes antes revisten la condición de «regantes», es decir, a todos aquellos propietarios de tierras que en el presente tienen asignados derechos de riego. Quienes, por el contrario, se localizan dentro de la cuenca y son potenciales usuarios pero no revisten la condición de «regantes» quedan apartados de la estructura del sistema de administración y carecen de reconocimiento formal para disputar caudales. Éste es el caso de los puesteros y comunidades huarpes de las tierras secas no irrigadas de Lavalle, situadas en la parte distal de la cuenca y por ello usuarios que al carecer de derechos de agua asignados por el DGI no revisten la condición de regantes y quedan apartados de la gestión institucionalizada del agua.

Si bien en variados documentos y planes oficiales de Mendoza $^{8}$, el agua posee valor social, económico y ambiental y constituye un bien del dominio público de la provincia -«... el recurso hídrico es uno de los principales factores para el crecimiento provincial, por lo que su planificación debe atender también a un desarrollo armónico que posibilite valorar y explotar las potencialidades existentes, y a la vez contribuir a la mitigación de las inequidades territoriales y sociales regantes» (DGI 2006)_; su administración y distribución se encuentra atravesada por relaciones de poder sumamente desiguales.

... la administración y gestión del sistema de riego constituye un poder de primera magnitud en la organización social y política de la sociedad mendocina. El manejo del recurso hídrico aparece como la principal bisagra de las relaciones espacio-sociedad y una expresión material y simbólica de las cadenas de dominación presentes...?

6. En la región existe una amplia bibliografía que considera objeto de estudio las funciones y logros del DGI a lo largo del tiempo. En varios casos se analizan además los impactos políticos y sociales que su gestión induce y los alcances efectivos que la «participación» de los regantes adquiere al interior del organismo, ya sea en perspectiva histórica como en relación al proceso descentralizador acaecido en la década de 1990.

7. Si bien escapa a los objetivos del presente trabajo y debe indicarse que varios autores dudan sobre los alcances y efectividad de la participación en el seno del DGI. Entre otros, R. M. BusTOS et al. (2006).

8. Se puede reconocer el Plan Estratégico de Desarrollo 2030 (PED); la Ley n. ${ }^{\circ} 8.051$ de Ordenamiento Territorial y Usos del Suelo con sus respectivos foros de trabajo; el Plan Director del río Mendoza del 2008, y el Plan Agua 2020, entre otros documentos oficiales.

9. E. MONTAÑA et al. (2005: 28). 
MARÍA VIRGINIA GROSSO CEPPARO Y LAURA MARÍA TORRES

En Mendoza, como en otros territorios de tierras secas, el agua fluye hacia el poder. Los flujos de agua, los del dinero y del poder se encuentran materialmente relacionados (Swyngedouw 2004), de forma tal que mientras el agua se mercantiliza y acapara en los territorios de oasis para emprendimientos agrícolas y/o inmobiliarios, las poblaciones ubicadas en el tramo inferior del río Mendoza no sólo conviven con limitadas dotaciones de agua, sino además con dispositivos discursivos, social y políticamente construidos, que atribuyen la responsabilidad exclusiva de la «escasez» a la naturaleza y racionalizan la dotación de agua en base a criterios de eficiencia y eficacia, prioritariamente definidos en el ámbito del mercado (Grosso 2013). Es que la escasez hídrica, vista sólo desde su explicación biofísica, constituye un dispositivo que ordena y legitima los procesos de apropiación, control y uso, al mismo tiempo que saca del campo de discusión la cuestión de las (des)igualdades social y políticamente construidas.

El concepto de escasez no es fácil de comprender, aunque lo utilicemos constantemente cuando hablamos de la asignación de recursos escasos. Por ejemplo, es discutible la existencia de una escasez surgida de modo natural (...) Si aceptamos que el mantenimiento de la escasez es esencial para el funcionamiento del sistema de mercado, aceptaremos entonces que la privación, la apropiación y explotación son consecuencias necesarias del sistema de mercado. En un sistema espacial, esto significa que habrá una serie de movimientos de apropiación entre territorios que hará que algunos territorios sean explotadores y otros explotados ${ }^{10}$.

Frente al exiguo régimen de lluvias que caracteriza la zona y hallándose severamente comprometidos los recursos hídricos superficiales, la reproducción social en los territorios lavallinos aparece ligada a la disponibilidad y accesibilidad a las aguas subterráneas. Emergen en el territorio, entonces, una amplia gama de dispositivos tecnológicos -prioritariamente orientados a la captación de agua y diseñados según un lenguaje técnico alejado de las modernas tecnologías de conducción y riego comunes en la parte alta de la cuenca-, entre los que destacan los pozos balde, los pozos manga y, en menor medida pero no importancia, los pozos jagüel.

Si bien en su conjunto se trata de dispositivos que dan cuenta de los saberes locales y hacen parte del patrimonio cultural de las tierras secas (Pastor 2005), el hecho de que se orienten a capturar aguas subterráneas enfrenta a los pobladores a dos situaciones problemáticas. De un lado, a la necesidad de asumir altos costos -tanto en dinero como en trabajo- para la construcción y mantenimiento de los dispositivos mismos; del otro, al hecho de que, en muchos casos, sólo se logra acceder a aguas subterráneas con altos niveles de salinidad y/o con presencia natural de arsénico (Pastor 2005).

Como modo de contrarrestar estas dificultades, los datos colectados a lo largo del trabajo de campo informan que en algunos casos la provisión de agua para consumo humano depende de recorrer $6 \mathrm{~km}$ a caballo, desde los puestos hasta «pozos balde» cercanos con agua de mejor -pero siempre relativa- calidad. La incorporación de rutinas

10. D. HARVEY (1985: 116). 
de este tipo al proceso de trabajo y (re)producción implica que las unidades domésticas deban destinar el trabajo de dos personas, cuatro horas por semana, para transportar a caballo cargas aproximadas de 80 litros de agua, sólo a los efectos de garantizar un consumo promedio, por día y persona, de entre 20 y 25 litros. En definitiva, una estrategia que implica altas dosis de tiempo/trabajo para arrojar saldos de consumo verdaderamente contrastivos a los 500 litros de consumo per cápita/día que se registran en las zonas de oasis (Grosso 2013) ${ }^{11}$.

Sólo en algunos casos, las dotaciones de agua subterránea son complementadas con aportes que asegura el municipio, a través de camiones cisterna que transportan agua de mejor calidad desde la zona irrigada. Sin embargo, por tratarse de una zona de médanos arenosos, que no siempre permite el traslado con vehículos de tracción simple, esta provisión queda reservada a los puestos que se localizan cercanos a las rutas (RP142) y que poseen caminos internos de acceso que resultan transitables. Se trata, aun así, de un «servicio» dependiente de terceros actores y no carente de limitaciones. Sólo a modo de ejemplo, en períodos de inclemencias climáticas se han constatado demoras superiores a los tres meses entre una y otra dotación, tiempo intermedio en el cual los pobladores se ven privados del recurso y deben recurrir al consumo mínimo de agua de baja calidad.

\section{EL «ACUEDUCTO DEL DESIERTO»: ¿SOLUCIÓN A LOS PROBLEMAS HÍDRICOS DE LAS TIERRAS NO IRRIGADAS?}

Frente a la necesidad de dar respuestas a la problemática hídrica que plantean los territorios del noreste provincial, en el año 2007, el Municipio de Lavalle se propone la conducción de agua a la zona a través del denominado «acueducto del desierto». Consiste en el tendido de una extensa red de cañerías que conectará las tierras no irrigadas con una perforación existente en la zona irrigada y que abastecerá a los principales poblados y puestos de la zona, reemplazando el actual sistema de camiones cisterna. El objetivo prioritario consiste en proveer al área de agua potable para consumo humano, dado el imperativo de atender las problemáticas vinculadas a la salud.

El proyecto recibió financiamiento del Gobierno Nacional, a través del Ente Nacional de Obras Hídricas de Saneamiento (ENOHSA) y del Municipio de Lavalle. Se

11. Diversos informes de organismos públicos locales denuncian consumos poblacionales superiores a 500 litros por habitante/día (1/hab./día). De acuerdo con el Centro de Economía y Administración del Agua (CELA), perteneciente al Instituto Nacional del Agua (INA), este valor es considerado falso ya que toma como referencia la cantidad de agua producida por la empresa, dividida el número de personas que sirve. Sus estimaciones indican valores menores, siendo los más frecuentes del orden de los 250 a 280 litros por persona/día. Si bien existen grandes usuarios que registran consumos superiores, amplios sectores de la población utilizan muy poca agua; pues se ven imposibilitados de aumentar el uso por las características de las conexiones y la presión del recurso (A. LLOP 2010). Asimismo, deben adicionarse las pérdidas en el servicio de distribución del agua potable por parte de las empresas y pequeños prestadores. 
planificó en dos etapas: una destinada a la realización de la red madre y otra a su puesta en funcionamiento a través de la instalación de las estaciones de bombeo y la interconexión de pueblos y puestos. Los lugares que recibieron agua potable son La Asunción, San José, Lagunas del Rosario, El Retiro, Reserva Natural y Cultural Bosques Telteca, El Cavadito, San Miguel, Lagunitas, El Retamo, El Forzudo y Arroyito.

En palabras de un funcionario del gobierno municipal, la idea de construir un acueducto surgió por la necesidad de buscar una solución de raíz y técnicamente posible a la problemática. Antes de adoptar la seleccionada, se consideraron diferentes alternativas, entre las que figuraban: a) la construcción de nuevos pozos; opción rápidamente descartada por considerarse que las aguas a las que se lograría acceder no tendrían la calidad necesaria; b) la provisión de agua potable desde la vecina provincia de San Luis a través de un acueducto que debía recorrer $20 \mathrm{~km}$; opción que logró factibilidad, pero luego se vio obstaculizada por problemas administrativos; c) la provisión de agua desde la provincia de San Juan, más específicamente desde el poblado de «El Encon», esta vez a través de un acueducto que nuevamente logró factibilidad pero no llegó a materializarse, y d) la instalación de una planta de ósmosis inversa, opción oportunamente descartada dados los altos costos que implicaba su instalación y la fragilidad que suponían las tareas de mantenimiento. Finalmente, las autoridades llegaron a la conclusión de que «la solución tiene que estar dentro del departamento, no podemos seguir planteando la dependencia de otro lado» ${ }^{12}$. La etapa de diseño demandó 2 años aproximadamente, ya que hubo que conciliar cuestiones técnicas y topológicas de la zona como, así también, presupuestarias ya que los montos iniciales eran inalcanzables para un pequeño municipio. Surge la necesidad entonces de solicitar financiamiento al gobierno provincial y/o nacional y recién en 2005 se logra incluir la obra en el presupuesto nacional, a través del ENOHSA. Según los acuerdos logrados, este organismo financiaría la obra, mientras el municipio licitaría los materiales y la construcción y aportaría mano de obra y maquinarias.

En una primera instancia de trabajo, el objetivo radicaba en dotar de agua potable a los pueblos y, a partir de ellos, a las escuelas y centros de salud. En una segunda instancia, se buscaría abastecer a los puestos adyacentes al acueducto, esto es, a aquellos que se localizan en un radio de aproximadamente $2.5 \mathrm{~km}$, mediante el uso de mangueras. Esa distancia constituye la máxima posible, en pos de asegurar presión al sistema en su conjunto.

Con una extensión total de $270 \mathrm{~km}$, que parten de la perforación y planta de potabilización situada en Gustavo André, la red madre llega al poblado de Asunción y, a la vera de la Ruta Provincial 142 o Ruta de las Altas Cumbres, se divide en dos tramos: una rama oeste, con rumbo hacia el norte, que atraviesa la localidad de San José y finaliza en Lagunas del Rosario y una rama este que se extiende casi hasta el límite con San Juan (El Puerto, ubicada frente a la localidad sanjuanina de El Encon) y que conecta los poblados de San Miguel, Lagunitas, El Retamo, El Forzudo y Arroyito. Por su parte, a mitad del trayecto se realiza un desvío de $32 \mathrm{~km}$ hacia el sureste, para alcanzar La

12. Fragmento de entrevista a funcionario público de la Municipalidad de Lavalle (2011). 
Majada y El Retiro, tramo éste que supuso las mayores complejidades en la ejecución por transitar sobre picadas de médanos de difícil acceso. Si bien en los inicios de la obra su recorrido fue pautado por el municipio con asesoramiento de organismos académicos vinculados a la problemática, las etapas de construcción supusieron modificaciones en la traza en virtud de los intereses y necesidades que los pobladores fueron sugiriendo.

La primera etapa de la obra (diciembre de 2007 a fines de 2008) constó del zanjeo y tendido de caños a lo largo de un recorrido de $170 \mathrm{~km}$ (tramo este, conexión con El Retiro, El Puerto y San Miguel y tramo oeste, conexión con Asunción y San José). La segunda etapa (2010-2011) demandó la construcción de 100 km, 36 km para conectar los poblados de San José y Lagunas del Rosario ${ }^{13}$ y el resto, para ampliar el tendido hacia las localidades ubicadas al este del departamento. De esta forma, entre la primera y segunda etapa y en el lapso de 4 años, el municipio logró concretar el tendido de $270 \mathrm{~km}$ de acueducto y la construcción de pozos subterráneos complementarios al de Gustavo André.

La tercera etapa, aún sin finalizar, prevé la adquisición de bombas, cargadores e hidrantes, para estabilizar la presión del sistema y abastecer in situ a los camiones cisterna que seguirán abasteciendo a los puestos más alejados y complementarán el servicio ante posibles eventualidades y un trayecto de $80 \mathrm{~km}$ que unirá al poblado de San Miguel con las localidades ubicadas a la vera del río Desaguadero. Por su parte, las variaciones en la traza que se han producido a lo largo del tiempo, crean dificultades para tener registros seguros sobre la cantidad de pobladores «servidos» por la obra, aunque el municipio estima conectar de forma directa a unas 200 familias, mientras otras 400 mejorarán sus condiciones de acceso por la mayor cercanía que lograrán a la nueva fuente de agua.

Mientras vamos avanzando, van surgiendo acuerdos con la gente por dónde llevar el caño... Desde que planteamos la construcción, la idea fue llegar a todas las localidades y conjuntos de viviendas consolidados pero después, por planteo de la gente, se fue cambiando la traza, a campo traviesa tocando los grupos de viviendas. Se va charlando con los puesteros la mejor traza. También esto ha tenido que ver con los caminos, hay una relación directa con los caminos que unen a todos los poblados de la zona desierto ${ }^{14}$.

Según los datos colectados a nivel municipal, los conflictos con las poblaciones locales han sido menores, dado básicamente a que la traza del acueducto pudo modificarse a medida que se avanzaba. Aun así se reconoce que existen 70 puestos que resultan completamente inaccesibles y con los que será necesario diseñar estrategias alternativas. Finalmente, una esfera de conflictos potenciales se aplaza al futuro; la relacionada con el cobro del servicio.

13. Si bien ya existía un acueducto con este recorrido, el municipio decidió hacer un nuevo trayecto al oeste del anterior, debido a la disponibilidad económica y porque existen 20 puestos allí que no son abastecidos por el acueducto anterior.

14. Fragmento de la entrevista con funcionario público de la Municipalidad de Lavalle (2011). 
Obviamente se va a cobrar, como cualquier hijo de vecino que tiene que comprar una casita de barrio y hay que pagar por el servicio. Todo se está viendo. La intención es que todos tengan un medidor, porque de lo contrario, en vez de seguir sacando agua del pozo balde para darle a las cabras, va a ser más fácil abrir la canilla y darles agua a las cabras de la cañería y no es la intención ${ }^{15}$.

El acueducto ha sido pensando para asegurar dotaciones de agua potable de 150 litros/habitante/día destinados a consumo, alimentos e higiene, en especial de quienes se localizan cercanos a la traza. Junto a las viviendas más alejadas del ducto, quedarán fuera del sistema de provisión la enorme cantidad de usos no humanos demandantes de agua, entre los que destaca el consumo ganadero. Por tratarse de una zona que exhibe un régimen de precipitaciones sumamente apretado, resulta previsible que, en épocas de sequía, el acueducto constituya si no la única la más segura fuente de agua para complementar los consumos animales. Quedan igualmente fuera de las previsiones iniciales el anhelo de algunos pobladores de contar con huertas destinadas al autoconsumo y con pequeños jardines que minimicen los efectos de la alta radiación.

... Llevo 34 años acarreando agua a caballo o en algún vehículo hasta mi puesto. Por eso es que conozco del esfuerzo que significa obtener agua que sea sana y no salada. Pero siempre tuve fe de que llegaría una red hasta este lugar. Esto nos permitirá cambiar la vida de la zona y nos traerá progreso... ${ }^{16}$.

Para las poblaciones locales, en particular para las que se localizan en Asunción, resta además esclarecer los valores de arsénico que poseen las aguas del acueducto, dado que tienen razones para dudar de ella y por el momento siguen proveyéndose del pozo del poblado «... todos dicen que tienen agua pero acá no hay análisis de si esa agua es potable o no es potable, si es buena o no es buena...» ${ }^{17}$.

\section{ACCIONES Y OMISIONES EN LA TRAMA DE ACTORES DEL ACUEDUCTO}

Más allá de los pobladores que reclaman resolver la provisión de agua potable y de las entidades que hasta ahora han participado en la construcción del ducto, la trama de actores que -por acción u omisión- han hecho de ésta la «solución posible» se complejiza si se considera en términos de las escalas. Dicho esto de otro modo, los actores que en el presente participan en la provisión de agua potable se desempeñan en diferentes escalas geográficas, en algunos casos se solapan en sus funciones, en otros casos dejan vacíos de gestión que marcan el surgimiento de nuevos actores en las tramas del agua potable.

15. Fragmento de la entrevista a concejal de Lavalle (2010).

16. Relato de poblador de la zona, recopilado en página web del Municipio de Lavalle (2011: http://www.lavallemendoza.gov.ar/.

17. Fragmento de la entrevista a poblador de Asunción (2013). 
MARÍA VIRGINIA GROSSO CEPPARO Y LAURA MARÍA TORRES ENTRE LAS POLÍTICAS POR EL AGUA Y LOS ESFUERZOS POR CALMAR LA SED

A nivel provincial, el servicio de agua potable se resuelve de la mano de tres tipos de prestadores. El 70\% del servicio es cubierto por la empresa Aguas Mendocinas (AYSAM) propiedad del Estado provincial, mientras el 30\% restante se resuelve por entidades de gestión municipal (Municipios de Luján de Cuyo, Maipú y Tupungato) $(15 \%)$ y comunitaria (uniones vecinales, cooperativas y consorcios) (15\%).

En el año 1993, Obras Sanitarias Mendoza Sociedad del Estado (OSM SE), principal prestadora del servicio de agua potable y saneamiento, fue privatizada (Ley n. ${ }^{\circ}$ 6044) y pasó a manos privadas como Obras Sanitarias Sociedad Anónima (OSM S.A.). A partir de entonces, sólo el 30\% de la empresa quedaba en manos del Estado provincial y el resto, en manos de capitales trasnacionales, con experiencia en el rubro, y de empresarios inmobiliarios locales, con una participación minoritaria. El único instrumento contractual de que disponía el sector público de Mendoza para exigir a la empresa privada que cumpliera con las obligaciones pautadas era un exhaustivo Plan de Operaciones y Expansión (POE), elaborado entre 1993 y 1998.

En él se señalaba la misión institucional de la empresa y se detallaban de manera minuciosa las obras y montos de las mejoras e inversiones que debían realizarse (Jofré 2010). Asimismo, el documento fijaba para la empresa las «áreas de servicio» (áreas servidas al momento de la privatización), las «áreas de expansión» (extensiones de 500 metros a partir de los ramales existentes) y las «áreas remanentes» (provistas por pequeños prestadores o librados a la autogestión), estableciéndose por este medio los territorios que debían ser abastecidos por la empresa y los territorios en los cuales su ausencia provocaba la aparición de nuevos actores. Aun hoy y luego de la reestatización de la empresa en 2010 (Aguas Mendocinas-AYSAM), este documento sigue pautando las áreas provistas y no provistas por el servicio en Mendoza.

En Lavalle, la provisión de agua potable sigue las pautas fijadas para la provincia, con la única excepción de que todas las áreas -de servicio, de expansión y remanentesse satisfacen con aguas subterráneas. Este hecho resulta cuando menos llamativo si se considera que el departamento se emplaza al interior de la cuenca del río Mendoza y que las demandas de agua potable resultan prioritarias según consta en la Ley de Aguas de Mendoza. Aun así y frente a la «escasez» que los organismos responsables declaran, el departamento debe recurrir a la extracción de caudales subterráneos.

En relación a las zonas de cobertura, una fracción de los territorios lavallinos -zonas urbanas y pequeñas fracciones rurales ubicadas en las zonas irrigadas- es abastecida por AYSAM, mientras el territorio restante, «remanente», es servido a través de 11 pequeños operadores. Entre éstos se ubican los extensos territorios no irrigados del departamento, incorporados al circuito de prestación que se desarrolla desde la localidad de Gustavo André luego de la concreción del acueducto y antes de lo cual, resolvía la totalidad de sus consumos en base a la extracción a título individual de aguas subterráneas.

El hecho de que en el presente sea una pequeña proveedora la que sirva a la zona no irrigada de Lavalle supone algunas ventajas, al mismo tiempo que sendas complejidades que hacen prever que el gobierno municipal deba mantener un activo papel en materia de obras y tareas de mantenimiento. 
Lo positivo de que el proveedor sea una cooperativa de Lavalle es que son gente de Lavalle que conoce Lavalle; sin embargo, si el servicio fuera provisto por un gran operador como AYSAM, contamos con que son especialistas en ese tema y que tienen capacidad económica y de respuesta. En cambio el pequeño operador ¿qué va a hacer?, planteárselo al municipio y nosotros gestionar el pedido en el ENOHSA... dependiendo de quien gobierne el municipio y quien gobierne la nación ${ }^{18}$.

El análisis de los datos obtenidos muestra que, mientras el acueducto se construye a instancias del gobierno nacional y municipal, el agua potable que éste distribuirá resulta asegurada por una cooperativa local, hallándose el Estado provincial ausente, incluso cuando cuenta en la zona con dependencias administrativas -centros de salud y escuelas- que enfrentan problemas de abastecimiento análogos a los de las poblaciones locales. El gobierno provincial, entonces, omite accionar en las instancias de construcción del acueducto y de provisión de agua potable a través de AYSAM, como también lo hace en la provisión de agua de riego a través del DGI.

Tiene que ver con todo un sistema que está mal. Por ahí las decisiones de planificación del Gran Mendoza resuelven algunas cuestiones del Gran Mendoza, pero aguas abajo... ¿viste la ley del gallinero?... si vas a dormir alguna vez en el gallinero no duermas abajo porque las gallinas de arriba... esa es la ley del gallinero... el que está abajo la lleva muy $\mathrm{mal}^{19}$.

Frente a un panorama de ausencias, el Municipio logró dotar de agua potable a los principales poblados, incluidas las escuelas y centros de salud. Sin embargo, las dificultades económicas para conectar los puestos a la red madre afectaron las intenciones iniciales. Frente a esta situación, un grupo de empresas mendocinas nucleadas en la Asociación Civil valOS Responsabilidad Empresaria ${ }^{20}$ iniciaron, a fines de 2010, una campaña de donación con el fin de conseguir fondos para comprar las mangueras y medidores que permitirían conectar a la red los puestos ubicados a menos de 2,5 $\mathrm{km}$. Bajo el lema «juntos podemos llevar agua potable a Lavalle» $\mathrm{y}$ «tu pequeño aporte logrará un gran cambio áreas de servicio», VALOS ofrecía una cuenta bancaria donde depositar las «donaciones», apelando para ello a la «solidaridad de los ciudadanos y empresas mendocinas».

18. Fragmento de la entrevista a concejal de Lavalle (2010).

19. Fragmento de la entrevista a concejal de Lavalle (2010).

20. VALOS posee como principal objetivo «contribuir desde el sector empresario a alcanzar una Mendoza sostenible, alentando relaciones sinérgicas, en una nueva forma de hacer negocios y promoviendo el desarrollo sostenible del medio». Por su parte, la responsabilidad empresaria es una forma de gestión que se define por la relación ética y transparente de la empresa con todos los públicos con los cuales se relaciona y por el establecimiento de metas empresariales compatibles con el desarrollo sostenible de la sociedad (http://www.valos.org.ar). 
Si bien la difusión de la campaña fue muy exigua en los medios locales ${ }^{21}$, adquirió algunas particularidades entre las que destaca el haber tematizado el reconocimiento de una deuda histórica del oasis respecto de los pueblos huarpes por las aguas del río Mendoza, luego de lo cual se indicaba que cabía el deber de «buscar una solución entre todos los mendocinos».

En la zona considerada la campaña contó con el apoyo, asesoramiento y conducción del cuerpo docente de un escuela de la zona -Escuela Comunitaria de Jóvenes y Adultos 3-235-, quienes tomaron a su cargo -junto a puesteros y estudiantes- la realización de reuniones y asambleas; la distribución de las donaciones; la realización de propuestas relacionadas a las trazas del acueducto en función de sus necesidades, constituyéndose además en voceros de las comunidades ante el municipio, la Cooperativa de Gustavo André y VALOS. De esta forma, mientras el municipio perdía participación en la provisión de los insumos necesarios para lograr el pleno funcionamiento del acueducto $^{22}$, aparecían una asociación civil y una escuela, además de los puesteros organizados.

En enero del 2011, cerca de 30 familias de El Cavadito recibieron las mangueras necesarias para conectarse al ducto. A través de los docentes de la escuela 3-235 y en presencia de funcionarios del municipio, se entregaron 23.000 metros de manguera y artefactos de instalación (Los Andes, uno de enero del 2011). Por su parte, estas familias se comprometieron a realizar las tareas de zanjeo y tendido de mangueras y el municipio, las conexiones formales al acueducto. Luego, llegarían las donaciones al poblado de La Majada y al Puerto, concretándose la conexión de 18 y 46 familias, respectivamente.

En febrero del 2011, por su parte, se llevó a cabo en El Puerto la primera reunión entre puesteros, municipio, docentes y cooperativa a propósito de la obra. En la misma, la prestadora explicó las características del servicio, los usos contemplados, la forma de almacenamiento del agua y el requisito excluyente de asociarse a la cooperativa; los docentes comentaron los detalles de la campaña de donación y la necesidad de organizarse como comunidad para la recepción y distribución de las cargas y para organizar las tareas de zanjeo e instalación. Los puesteros se interiorizaron de la traza prevista, propusieron mejores opciones y evidenciaron la situación particular de algunos puestos alejados, que presentaban fuertes necesidades de agua. El municipio, finalmente, asesoró técnicamente sobre los diámetros de manguera necesarios y la traza básica con el fin de no perder presión de agua en el afán de expandir el servicio.

En mayo del 2011, llegó a El Puerto el camión con 140 rollos de manguera que fueron recibidos por una organización comunitaria, en la que recayeron las tareas de distribución. El día pautado se reunieron en el centro del poblado más de 50 familias y se dieron a la tarea de organizar subgrupos en función de la cercanía en las localizaciones,

21. Diario Los Andes 1/2/2011 y diario MDZ: http://www.mdzol.com/nota/276998-la-deudamas-ominosa-de-la-historia-de-mendoza/ y http://www.mdzol.com/nota/294300-romeos-julietas-yuna-historia-de-amor-de-300-anos-y-miles-de-kilometros-de-largo/.

22. Si bien el municipio ve resentida su participación en esta etapa, sigue siendo un actor principal dado que se reserva la capacidad de aceptar o rechazar extensiones de la red que impliquen menos presión de agua para el sistema en su conjunto. 
establecer un croquis detallando la traza que seguiría el «acueducto vecinal» y establecer la cantidad de mangueras que cada familia necesitaba para conectarse.

En menos de tres horas, la distribución del material logró concretarse y las familias partieron luego de asumir el compromiso de realizar los zanjeos correspondientes en forma asociativa para que, en un término de no más de un par de semanas, pudiesen conectarse al acueducto. Como bien menciona un docente de la escuela, «el esfuerzo de varios mendocinos solidarios llegó a sus destinarios directos. Éstos lograron reunir, trasladar y entregar otro camión de mangueras como pequeño pero significativo y comprometido aporte, que contribuye a devolver a más de 100 familias, en esta etapa el agua de todos los días que la ciudad les quitó».

Y es, quizás, el reiterado uso del término «devolver» el que vuelve complejo el relato de la campaña de donación en tierras lavallinas. Si bien la donación de mangueras constituye un interesante esfuerzo de parte de algunos sectores de la sociedad civil y que probablemente atenúe la falta de agua, no puede sino invitar a reflexión el hecho de que se trate de un esfuerzo solidario que se hace necesario por la previa ausencia del Estado. Dicho esto de otro modo, aun cuando resulta plausible que la ausencia de Estado active lazos de solidad intra- e interterritorial, no puede pasar inadvertida su ausencia misma allí donde el agua constituye un derecho humano de primer orden. Y es que, tal vez como sugiere Godelier (1998), en las modernas sociedades capitalistas la misma economía que genera excluidos confía en que la sociedad favorece su reinclusión, no a la economía sino a la sociedad misma, delegando en otros la función que deja vacante el Estado cuando se declara impotente de reducir las fracturas y brechas sociales.

\section{CONCLUSIONES}

El objetivo propuesto al inicio del trabajo consistió en problematizar el «acueducto del desierto», como «solución» a la «falta de agua». Se preguntaban, entonces, si este dispositivo tecnológico, pero también político, situaba a las tierras secas frente a renovadas políticas por el agua, orientadas a extender los principios de la soberanía hídrica, entendida como la posibilidad de hacer uso de los bienes naturales priorizando la reproducción social de la vida por sobre la reproducción del capital, o a políticas sólo dispuestas a calmar la sed.

Los recorridos realizados nos han permitido constatar que tanto en lo referido a las dotaciones de agua potable y de riego como en torno al proceso de diseño, construcción e implementación del acueducto, cuenta como gran ausente el gobierno provincial; ausencia ésta que da paso a la emergencia de actores diversos que ensayarán respuestas alternativas a la falta de agua. El municipio, ensayando respuestas a los graves problemas de abastecimiento que sus poblaciones rurales exhiben; el Estado nacional, acompañando con recursos financieros las iniciativas locales; donantes, que toman a su cargo las últimas etapas de la obra, y pobladores, consensuando trazas, distribuyendo donaciones y aportando su propio trabajo. Frente a una trama de ausencias, el acueducto constituye un dispositivo tecnológico que atenúa la sed y en cuya construcción concurren actores no carentes, consistentes, constructores de territorio. 
Aun así, en la medida en que el acueducto se plantea en términos de beneficiarios y no de sujetos de derecho, no hace parte de la política hídrica provincial ni queda, mucho menos, planteado como parte de las acciones de reparación histórica a las que tienen derecho estos actores y territorios, queda a mitad de camino en el ejercicio de la soberanía hídrica y no logra disputar la apropiación y control de bienes naturales vitales, como el agua.

La ausencia del gobierno provincial, frente a las demandas de restitución de derechos que emanan de las poblaciones asentadas en la cola de la cuenca, lo ubican entonces a años luz de la posibilidad y tal vez de la intención de actuar en el nivel de las causas del problema y en el sentido de la reparación histórica de las poblaciones. Por el contrario, lo (re)ubican en las posiciones que históricamente asumió como gran conductor de aguas a los contornos del poder/dinero. Por detrás de esta ausencia, el discurso de la escasez sigue dejando su impronta en el territorio, porque vincula el origen de la falta de agua en Lavalle a factores biofísicos y presenta esta ausencia como algo inevitable, natural y normal, propio del lugar, a la que sólo resta acomodarse. Por tratarse de un «problema local y particular», al mismo tiempo que «natural», el Estado provincial se inhibe de cualquier responsabilidad, incluso de la de participar en la construcción del acueducto.

Complementariamente, el trabajo ha permitido observar que las sendas discusiones que en Mendoza ha suscitado el agua para riego se profundizan en relación al agua potable, una problemática menos indagada a nivel regional. La imposibilidad de Lavalle de hacer uso de las aguas superficiales del río Mendoza para abastecer sus consumos de agua potable, tanto en el oasis como en las tierras no irrigadas, evidencia las dimensiones que pueden adquirir las disputas por el agua en contextos de tierras secas. En definitiva, no puede sino observarse la paradoja que significa que el Estado provincial asegure caudales para riego en la cuenca superior del río que serán en gran medida exportados -previa transformación en vinos premium- y omita asegurar caudales para consumo humano en su parte distal, asintiendo por omisión que allí los consumos deban resolverse a instancia local y con aguas subterráneas contaminadas con arsénico.

\section{BIBLIOGRAFÍA}

ABRAHAM, Elena María. Paleocauces y posibles conexiones entre los ríos Mendoza y Tunuyán, por filtrado bidimensional de imágenes LANDSAT. En MENENTI, Manuel (ed.). Mecanismos de aprovechamiento hidrico en la región andina. Modelos de simulación e imágenes satelitarias. Mendoza: ICW-INCYTH, 1989: 283-299.

ABRAhAm, Elena; RUBIO, Cecilia; SALOMÓN, Mario y SORIA, Darío. Desertificación: problema ambiental complejo de las tierras secas. En TORRES, Laura; ABRAHAM, Elena María y PASTOR, Gabriela (eds.). Ventanas sobre el territorio. Herramientas teóricas para comprender las tierras secas. Mendoza: EDIUNC, 2014: 187-265.

BALAZOTE, Alejandro y RADOVICH, Juan Carlos. Proyecto Mega: disputa territorial y reconocimiento étnico en Kaxipayiñ. Relaciones, Buenos Aires, 2004, tomo XXVI: 107-117.

Bustos, Rosa María; YÁÑEZ, Lilibeth; DE ROSAS, María Laura y SALDI, Leticia. Redes sociales, capital social y clientelismo político en las organizaciones de usuarios de riego de la Provincia de Mendoza-Argentina. Mendoza: Pre ALAS, Universidad Nacional de Cuyo, 2006. 
CAMPI, Daniel y RiCHARD JORBA, Rodolfo. Transformaciones productivas, espaciales y sociales en la Argentina extrapampeana, 1850-1890. Boletín Americanista, 2004, (54): 35-61.

CHAmBOUlEYRON, Jorge. La cultura del agua: de la acequia colonial a los grandes embalses. En Roig, Arturo; LaCoste, Pablo y SATLARI, María Cristina (comps.). Mendoza, cultura y economía. Mendoza: Editora Caviar Bleu, 2004: 116-144.

Departamento General de IrRigación (DGI). Plan Director del Río Mendoza. Proyecto PNUD/FAO/ARG/00/008. 2006: en línea: www.irrigacion.gov.ar. Fecha de consulta 01/04/2012.

GODELIER, Maurice. El enigma del don. Barcelona: Paidós, 1998.

Grosso, Virginia. Vivir sin agua. Estrategias frente a la escasez en las tierras secas no irrigadas de Lavalle, Mendoza. Revista de la Carrera de Sociología. Entramados y Perspectivas, 2013, 3 (3): 13-39.

HARVEY, David. Urbanismo y desigualdad social. Tercera edición. Madrid: Siglo XXI de España Editores S.A., 1985 [1977].

Hocsman, Luis Daniel. Reproducción Social Campesina: tierra, trabajo y parentesco en el Chaco Árido Serrano. Córdoba: Centro de Estudios Avanzados, Universidad Nacional de Córdoba, 2003.

INDEC. Censo Nacional de Población y Vivienda, Gobierno de Mendoza, 2010.

Jofré, José Luis. Obras Sanitarias Mendoza: de Empresa privada a Pública. Plataforma de información para políticas públicas, UNCuyo, 2010: en línea: www.politicaspublicas.uncu.edu.ar. Fecha de consulta: 05 de junio del 2013.

LlOP, Armando. Evaluación de los Impactos Esperados y Vulnerabilidad al Cambio Climático de los Recursos Hídricos en lo referido a Oferta y Demanda de Agua en la Provincia de Mendoza, República Argentina. Para el Informe Nacional Argentino para el Estudio Regional de la Economía del Cambio Climático en Sudamérica. EREC-SA, 2010.

MONTAÑA, Elma; TORRES, Laura; ABrAHAM, Elena; TORRES, Eduardo y PASTOR, Gabriela. Los espacios invisibles. Subordinación, marginalidad y exclusión de los territorios no irrigados en las tierras secas de Mendoza, Argentina. Revista Región y Sociedad, 2005, vol. XVIII (32): $1-32$.

PASTOR, Gabriela. Patrimonio, vivienda y agua en el paisaje del Noreste de Mendoza. En FERNÁNDEZ CIRELLI, Alicia y ABRAHAM, Elena (eds.). El agua en Iberoamérica. Uso y gestión del agua en tierras secas. Mendoza: CYTED, 2005: 79-92.

RADOVICH, Juan Carlos y BALAZOTE, Alejandro. Multiculturalidad y Economía: El caso del Interfluvio Teuco-Bermejito. RUNA, 2001, vol. XV: s/p.

RICHARD JORBA, Rodolfo. ¿Echar raíces o hacer la América? Un panorama de la inmigración europea hacia la región vitivinícola argentina y algunos itinerarios económicos en la provincia de Mendoza, 1850-1914. En CozZANi DE PALMADA, María del Rosario (coord.). Migrations en Argentina II. Saint-Denis: Cahiers ALHIM, 2004: 113-142.

SwINGEDOUW, Erik. Social Power and the Urbanization of Water: Flows of Power. 1. ${ }^{a}$ edición. Oxford: Oxford University Press, 2004.

TORRES, Laura. Hilos de agua, lazos de sangre: enfrentando la escasez en el desierto de Lavalle (Mendoza, Argentina). Ecosistemas, 2008, vol. 1: 46-59. 